\title{
Who First Suggests the Diagnosis of Attention-Deficit/Hyperactivity Disorder?
}

\author{
Leonard Sax, MD, PbD \\ Katbleen J. Kautz, RN, BSN \\ Montgomery Center for Research in Child \\ and Adolescent Development (MCRCAD), \\ Poolesville, Md
}

\begin{abstract}
PURPOSE We wanted to survey physicians in the Washington, DC, metropolitan area regarding the frequency with which physicians, teachers, parents, and others first suggest the diagnosis of attention-deficit/hyperactivity disorder (ADHD).
\end{abstract}

METHODS A questionnaire was mailed to all family physicians, primary care pediatricians, and child psychiatrists in greater Washington, DC. In answer to the question, "Who first suggests the diagnosis of ADHD?" respondents assigned percentages to primary care physicians, consultants, parents, teachers, etc.

RESULTS Teachers were most likely to be first to suggest the diagnosis of ADHD (46.4\%; 95\% Cl, 44.1\%-48.7\%), followed by parents $(30.2 \%$; $95 \% \mathrm{Cl}, 28.3 \%-$ $32.0 \%)$, primary care physicians $(11.3 \% ; 95 \% \mathrm{Cl}, 9.7 \%-12.8 \%)$, school personnel other than teachers $(6.0 \% ; 95 \% \mathrm{Cl}, 4.9 \%-7.2 \%)$, consultants such as child psychiatrists or psychologists (3.1\%; $95 \% \mathrm{Cl}, 2.3 \%-3.9 \%)$ and other specified categories $(3.0 \% ; 95 \% \mathrm{Cl}, 2.4 \%-3.6 \%)$.

CONCLUSIONS Teachers and other school personnel are often the first to suggest the diagnosis of ADHD in children in the greater Washington, DC, area. Regional variations in the prescribing of medication for ADHD may be caused at least in part by variations in the likelihood of a teacher suggesting the diagnosis of ADHD.

Ann Fam Med 2003;1:171-174. DOI: 10.1370/afm.3

\section{INTRODUCTION}

$\mathrm{T}$ The prescribing of medication for attention-deficit/hyperactivity disorder (ADHD) has increased substantially in the United States during the past 10 years. The amount of methylphenidate (eg, Ritalin, Concerta) prescribed in the United States increased by more than $500 \%$ between 1991 and 1999, while the prescribing of amphetamines (eg, Dexedrine, Adderall) increased by more than 2000\% during the same interval. ${ }^{1}$ The number of physician office visits devoted to evaluating and treating children with ADHD also increased during this time period, although by a smaller amount. For girls, the number of ADHD-related office visits increased threefold between the beginning of 1990 and the end of 1998; for boys, a 2.2-fold increase occurred in ADHD-related office visits during the same period. ${ }^{2}$

Several studies have found wide regional variation in the prescribing of stimulants for the treatment of ADHD., ${ }^{3,4}$ Some authors have questioned whether all children receiving medication for ADHD actually meet standard diagnostic criteria for ADHD. One study of students in North Carolina found that only $43 \%$ of students taking medication for ADHD met the Diagnostic and Statistical Manual of Psychiatric Disorders (DSM-III-R) criteria for ADHD. ${ }^{5}$ An investigator commenting on this paper conjectured that "parents and teachers may be lobbying doctors to write stimulant prescriptions in the hope that they will help children do better in school."6

Few published studies have attempted to delineate the process by which children are diagnosed and treated for ADHD in community set- 
tings, as opposed to the setting of the referral clinic. In particular, we are not aware of any published study that has attempted to determine, on a regional or national basis, how often and to what extent teacher recommendations and parental preferences play a role in the diagnosis or treatment of ADHD.

A scholarly commentary on this topic concluded that "research is urgently needed to elucidate the most common pathways leading to children's referral, diagnosis, and treatment [for ADHD] and to evaluate the impact on this process by variables such as parental perception of impairment, social and academic expectations, [and] schools' attitudes. ..." 7

We conceived this project as an initial effort to study one aspect of "the most common pathways leading to referral, diagnosis, and treatment" ${ }^{\prime \prime}$; namely, who first suggests the diagnosis of ADHD? We reasoned that the most cost-effective approach to an initial study of this question would be to survey physicians, while recognizing that it would be useful in the future to survey teachers and parents as well. For this study, we surveyed family physicians, primary care pediatricians, and child psychiatrists in the greater Washington, DC, area (Washington, DC, suburban Maryland, and northern Virginia).

\section{METHODS}

\section{Selection of Survey Recipients}

The Wasbington Pbysicians Directory (Silver Spring, Md), lists all licensed physicians practicing in the greater Washington, DC, area, including the District of Columbia, suburban Maryland, and northern Virginia. For this survey, we obtained mailing labels for all family physicians, pediatricians, and child psychiatrists with office locations in the District of Columbia, in northern Virginia, and in Prince Georges County, Maryland, and Montgomery County, Maryland.

Surveys were sent to all family physicians, primary care pediatricians, and child psychiatrists in these areas. We defined primary care pediatricians as pediatricians who were not listed as subspecialists and followed the directory in defining a family physician as any physician who describes herself or himself as a family physician.

\section{The Survey}

The survey instrument was an anonymous, 1-page questionnaire asking physicians to "Please estimate, by percentages, the frequency with which each of the following first suggests the diagnosis of ADHD to the parents: $\mathrm{MD}$ primary-care provider, $\mathrm{MD}$ consultant, teachers, other school personnel, parents, other relatives, neigh- bors, professional caregivers, and other. Please specify." Physicians also were asked, "For what percentage of children whom you diagnose with ADHD do you also recommend medication?" Surveys were mailed on September 24, 2001. No follow-up surveys were mailed.

\section{Statistical Analysis}

All analyses were performed using ASP software (DMC Software, Grand Blanc, Mich). The statistical method employed was a fixed-effects analysis of variance, with 3 factors: jurisdiction (Maryland, Virginia, or the District of Columbia), specialty (pediatrics, family practice, or child psychiatry), and sex of respondent. Significant differences were determined at $P<.05$.

\section{RESULTS}

\section{Response Rates}

Surveys were sent to 512 family physicians, 412 primary care pediatricians, and 165 child psychiatrists (1,089 total). A total of 491 responses were received, which yielded an overall response rate of $45 \%$.

Response rates varied as a function of specialty. Primary care pediatricians had the highest response rate $(54 \%)$; child psychiatrists had a response rate of $34 \%$, and family physicians had a response rate of $30 \%$.

\section{Percentage of Children Taking Medication for ADHD}

Family physicians estimated that $6.9 \%$ of the children in their practice were taking medication for ADHD (95\% CI, 6.6\%-7.1\%). Pediatricians estimated that $10.8 \%$ of children in their practice were taking medication for $\mathrm{ADHD}$ (95\% CI, 10.6\%-11.0\%), while child psychiatrists estimated that $55.6 \%$ of children in their practice were taking medication for ADHD (95\% CI, 55.0\%-56.2\%). These differences between specialties were highly significant $(P<.0001)$. No significant differences were noted between jurisdictions or between female and male physicians who responded.

\section{Proportion of Children Who Were Boys}

Respondents estimated that $75.4 \%$ of children taking medication were boys (95\% CI, 74.1\%-76.7\%). The jurisdiction, specialty, or sex of the respondent physician had no significant effects.

\section{Who First Suggests the Diagnosis of ADHD?}

Teachers were the most likely to be the first to suggest the diagnosis of ADHD, followed by parents, primary care physicians, school personnel other than teachers, MD consultants, paid caregivers other than relatives, relatives other than parents, neighbors, and 


\begin{tabular}{ll|}
$\begin{array}{l}\text { Table 1. Doctors' Estimates: Who First Suggests } \\
\text { the Diagnosis of ADHD? }\end{array}$ \\
\hline Group & Percent $(95 \% \mathrm{Cl})$ \\
Teachers & $46.4(44.1-48.7)$ \\
Parents & $30.2(28.3-32.0)$ \\
Primary care physicians & $11.3(9.7-12.8)$ \\
School personnel other than & $6.0(4.9-7.2)$ \\
teachers & \\
MD consultants & $3.1(2.3-3.9)$ \\
Paid caregivers & $1.1(0.7-1.5)$ \\
Relatives (other than parents) & $1.1(0.7-1.5)$ \\
Neighbors & $0.6(0.4-0.8)$ \\
Other & $0.3(0.1-0.5)$ \\
\hline
\end{tabular}

"other" (see Table 1). Only one significant effect of specialty $(P<.001)$ was noted. Child psychiatrists were significantly more likely to indicate MD consultants as being the first to suggest the diagnosis of ADHD. Child psychiatrists indicated MD consultants in 9.6\% of cases (95\% CI, 9.3\%-9.9\%). Pediatricians indicated $\mathrm{MD}$ consultants in $2.7 \%$ of cases $(95 \% \mathrm{CI}, 2.6 \%$ $2.8 \%)$, and family physicians did so in just $1.2 \%$ of cases (95\% CI, $1.1 \%-1.3 \%)$.

\section{In What Percentage of Children With ADHD is Medication Prescribed?}

Overall, physicians estimated that they prescribed medication for $77 \%$ of patients diagnosed with ADHD (95\% CI, 75\%-79\%). The physician's specialty had a significant effect $(P<.001)$. Child psychiatrists prescribed medication for $88 \%$ of children diagnosed with ADHD (95\% CI, 87\%-89\%); the corresponding figure was $77 \%$ (95\% CI, 76\%-78\%) for pediatricians and $72 \%$ for family physicians (95\% CI, 71\%-73\%). No significant differences between respondents from Maryland, Virginia, and the District of Columbia were noted, and no differences between female and male respondents were noted.

\section{DISCUSSION}

Physicians who responded to our survey estimated that the diagnosis of ADHD was first suggested by a teacher or other school employee in about one half of those children so diagnosed. Physicians estimated that the diagnosis was first suggested by a parent in about one third of cases.

Are teachers and parents more likely to consider that diagnosis now than they were 10 years ago? If so, why? $\mathrm{Sax}^{8}$ has documented a shift in the kindergarten and early elementary curriculum during the past 10 to
20 years, from a play-based curriculum to a more academically oriented curriculum, with the major emphasis today being the early acquisition of literacy skills. Sax suggests that this shift to a more academic curriculum in early elementary education may be partly responsible for the increased propensity of teachers to suggest the diagnosis of ADHD, as well as the increased willingness of parents to consider stimulant medication for their children. ${ }^{8}$ An academically oriented kindergarten, in which 5 -year-old children are expected to sit at a desk and do paper-and-pencil exercises, poses a major challenge for some children. A child who is fidgety and inattentive in such a classroom might well be labeled "ADHD" by the teacher, when in fact that child may have no underlying psychopathology but merely needs a more developmentally appropriate curriculum. If Sax's hypothesis is correct, then we should find that teachers in an academically oriented kindergarten are more likely to suggest the diagnosis of ADHD than are teachers in a play-based curriculum. This hypothesis remains to be tested.

\section{Limitations}

Three major limitations may affect the generalizability of these results. First, we do not know the accuracy of the estimates made by the physicians. Second, we do not know to what extent the greater Washington, DC, area is representative of the nation as a whole in this regard. Maryland and Virginia rank among the top 10 states nationwide in per capita consumption of prescription methylphenidate and prescription amphetamines. ${ }^{1}$ A larger follow-up study, surveying physicians nationwide, would be helpful. Third, our survey did not achieve a high response rate $(45 \%$ overall). However, the variance in the responses was remarkably small; within specialties, responses were unexpectedly similar. The CIs for the means were correspondingly narrow. For that reason, we doubt that a higher response rate would have markedly altered the results.

\section{Clinical Implications}

If it is indeed the case that teachers are often the first to suggest the diagnosis of ADHD, further investigation is appropriate to determine teachers' accuracy in suggesting that diagnosis. In one recent study ${ }^{9}$ of teachers in urban and rural settings, teachers collectively identified $23 \%$ of boys in their classrooms as having ADHD. In discussing this unexpectedly high prevalence, the authors of the study speculated that "teachers may have confused ADHD behaviors with other problems, eg, low IQ, anxiety, [and] psychosocial stressors." 9 Teachers in this study also were about 3 times as likely to diagnose black elementary school children with ADHD as they were to diagnose white 
children with the disorder. Most other studies of the prevalence of ADHD have found either no racial disparity, or have found ADHD to be more prevalent among white children. ${ }^{10}$

Further research would help to determine how often teachers are first to suggest the diagnosis of ADHD. It is possible that regional variations in the prescribing of medication for ADHD may be due at least in part to variations in the likelihood of a teacher suggesting the diagnosis of ADHD.

To read commentaries or to post a response to this article, see the online version at http://annfammed/cgi/content/full/1/3/171.

Key words: Attention-deficit hyperactivity disorder; teachers; parents; stimulant medication; behavioral/psychosocial

Submitted September 10, 2002; submitted, revised, December 6, 2002 accepted January 1, 2003

\section{Financial support}

This work was supported by grant G0112RS from the Foundation of the American Academy of Family Physicians.

\section{References}

1. Woodworth T. Ritalin use among youth: hearing before the Subcommittee on Early Childhood, Youth, and Families of the House Committee on Education and the Workforce, 106th Congress, 2nd Session, 16 May 2000. Testimony of Terrance Woodworth, Deputy Director, Office of Diversion Control, Drug Enforcement Administration. Available at http://edworkforce.house.gov/hearings/106th/ecyf/ ritalin51600/woodworth.htm. Accessed April 29, 2003.

2. Robison LM, Skaer TL, Sclar DA, Galin RS. Is attention deficit hyperactivity disorder increasing among girls in the US? Trends in diagnosis and the prescribing of stimulants. CNS Drugs 2002;16:129-137.

3. LeFever GB, Dawson KV, Morrow AL. The extent of drug therapy for attention deficit hyperactivity disorder among children in public schools. Am J Public Health 1999;89:1359-1364.

4. Burton TM. Prescription drug use varies widely from state to state. Wall Street Journal June 19, 2001:B4

5. Angold A, Erkanli A, Egger HL, Costello EJ. Stimulant treatment for children: a community perspective. J Am Acad Child Adolesc Psychiatry 2000:39:975-984.

6. Vitiello $B$, in Marshall M. Duke study faults overuse of stimulants for children. Science 2000;289:721.

7. Vitiello B. Commentary. J Am Acad Child Adolesc Psychiatry 2000; 398:992-994.

8. Sax L. Reclaiming kindergarten: making kindergarten less harmful to boys. Psychol Men Masculinity 2001;2:3-12.

9. Nolan ED, Gadow KD, Sprafkin J. Teacher reports of DSM-IV ADHD, ODD, and CD symptoms in schoolchildren. J Am Acad Child Adolesc Psychiatry 2001;40:241-249.

10. Scahill L, Schwab-Stone M. Epidemiology of ADHD in school-age children. Child Adolesc Psychiatr Clin N Am 2000;9:541-555. 